\title{
Role of High frequency oscillatory mode of ventilation (HFOV) as a rescue treatment in newborns with impending respiratory failure after failed conventional mode of ventilation
}

\author{
Venkatesh Murthy D V', Benakappa $\mathbf{N}^{2}$, Benakappa $\mathrm{A}^{3}$ \\ ${ }^{1}$ Dr. Venkatesh Murthy Dammaningala Venkataramaiah, Resident, Department of Paediatrics, South Hospital Complex, \\ Dharmaram College Post (Near Nimhans), Indira Gandhi Institute of Child Health, Bangalore, ${ }^{2}$ Dr. Naveen Benakappa, \\ Professor, Department of Paediatrics, Indira Gandhi Institute of Child Health South Hospital Complex, Dharmaram \\ College Post (Near Nimhans), Bangalore, ${ }^{3}$ Dr. Asha Benakappa, Dean cum Director, Indira Gandhi Institute of Child \\ Health South Hospital Complex, Dharmaram College Post (Near Nimhans), Bangalore, Karnataka, India.
}

Address for Correspondence: Dr. Venkatesh Murthy Dammaningala Venkataramaiah, No 374, Venkateshwara Nilaya, $5^{\text {th }}$ Main Road, 3rd Block, 3rd Stage, Basaveshwaranagar, Bangalore. Email Id: venkateshmurthy99@gmail.com

\begin{abstract}
Introduction: High frequency oscillatory ventilation (HFOV) is a new mode of mechanical ventilation which by safer use of mean airway pressure higher than that used during conventional ventilation (CV) is better lung safety strategy in respiratory failure. Aims and Objectives: To study the role of high frequency oscillatory ventilation at a tertiary NICU as rescue mode in neonates with severe respiratory failure. Materials and Methods: 31 neonates admitted in NICU failing conventional mode of ventilation were studied prospectively from January 2014 to September 2015. Babies with respiratory failure failing conventional mode of ventilation were shifted to HFOV. On HFOV, babies were initially started on mean airway pressure $2 \mathrm{~cm}$ higher than on conventional ventilation and increased until a saturation of $>95 \%$ is achieved. Neonates were again weaned off to $\mathrm{CV}$, when target goals of oxygenation and ventilation were reached. Improvements were assessed periodically by arterial blood gas analysis (ABG) and other parameters. Results: 31 neonates were shifted to HFOV as rescue therapy and primary outcome was improvement in oxygenation index and alveolar arterial oxygen radiant $\left(\mathrm{A}-\mathrm{aDO}_{2}\right)$ which were compared and also showed significant impact on secondary outcome of survival. Majority of neonates with primary diagnosis as meconium aspiration syndrome, congenital pneumonia showed $100 \%$ recovery. PPHN babies had $78 \%$ recovery, while babies with pulmonary haemorrhage had poor outcome. There was statistically significant improvement in oxygenation index and $\mathrm{A}-\mathrm{aDO} 2$ in 15 babies after shifting to HFOV. Thus, the study shows that HFOV can be used as rescue therapy for neonates after failing conventional ventilation.
\end{abstract}

Keywords: High Frequency Oscillatory Ventilation, Conventional ventilation, Oxygenation index, AaDO2 gradient, Mean airway pressure

\section{Introduction}

Every year, four million babies die in the first month of life $-99 \%$ in low and middle income countries [1,2]. In India, neonatal deaths constitute two thirds of deaths, $45 \%$ of deaths occurring within first two days of life [3]. Pulmonary disease is a major cause of mortality and morbidity in term and near term infants [4]. As a result of medical and surgical advances, improvement in mortality rates have occurred and ventilatory

Manuscript received: $20^{\text {th }}$ October 2016

Reviewed: $4^{\text {th }}$ November 2016

Author Corrected; $18^{\text {th }}$ November 2016

Accepted for Publication: $30^{\text {th }}$ November 2016 intervention also constitute one of the mode of intervention. Conventional mode of ventilation either in the form of pressure or volume cycled by patient triggered or mandatory modes in the treatment of neonatal respiratory failure is undisputed.

The limitations of conventional mode of ventilation in treatment of newborns with respiratory failure demand the development of lung protective strategies in the form of high frequency oscillatory mode of ventilation. High frequency oscillatory ventilation (HFOV) has 
been successfully used in neonates and paediatrics since 1983. HFOV is an alternative form of mechanical ventilation that can be delivered on critical newborn care units which relies on rapid delivery of tidal volumes that are smaller than dead space. Studies have shown higher survival rates in acute respiratory distress syndrome (ARDS) [5,6]. In animal models, the use of HFOV results in more uniform lung inflation, improves oxygenation and reduces the severity of lung pathology produced by conventional ventilation $[7,8]$.

Principle of HFOV: Gas transport on HFOV as suggested by Weavind and Wenker in 2000 occurs by 5 pathomechanisms namely bulk flow, pendelluft effect, Taylor dispersion, coaxial flow and molecular diffusion [9]. During HFOV, oxygenation and ventilation are decoupled. Oxygenation is primarily a function of fraction of inspired oxygen (FiO2) and peak airway pressure (PAW optimises alveolar surface for gas exchange). PAW during HFOV is a clinician set value which can be changed [10]. Similarly, higher frequencies 120-600 breaths per minute in comparison to 40 breaths per minute for $\mathrm{CV}$, allows use of tidal volumes which otherwise lead to rising PCO2 levels in $\mathrm{CV}$. Since tidal volume affects $\mathrm{CO} 2$ elimination, it can be controlled with frequency setting in HFOV and enable clinician in optimising lung inflation [11,12]. Thus, HFOV by principle of rapid delivery of tidal volumes smaller than dead space, typically $1-3 \mathrm{ml} / \mathrm{kg}$ keeps lung open, improves outcomes by decreasing shear forces associated with repetitive opening of collapsed alveoli.

However, the largest trial was Health HiFi trial till date and HFOV is being used less often in India due to inadequate evidence with regards to its efficacy, necessitating increasing need to study the role of this in neonates [13]. Thus present study was conducted to ascertain the role of HFOV in newborns with impending respiratory failure after conventional ventilation.

\section{Methods and Materials}

31 neonates admitted in NICU with severe respiratory failure requiring ventilatory support and failing conventional mode of ventilation were studied prospectively from January 2014 to September 2015. The study was approved by the institutional ethical committee review board and informed consent was taken from the parents. All neonates with gestational age more than 34 weeks and weight more than $1000 \mathrm{gm}$ presenting with severe respiratory failure after failed conventional mode for 6 hrs were included whereas infants with life threatening congenital malformations were excluded from the study. Figure 1 represents the protocol followed in the study.

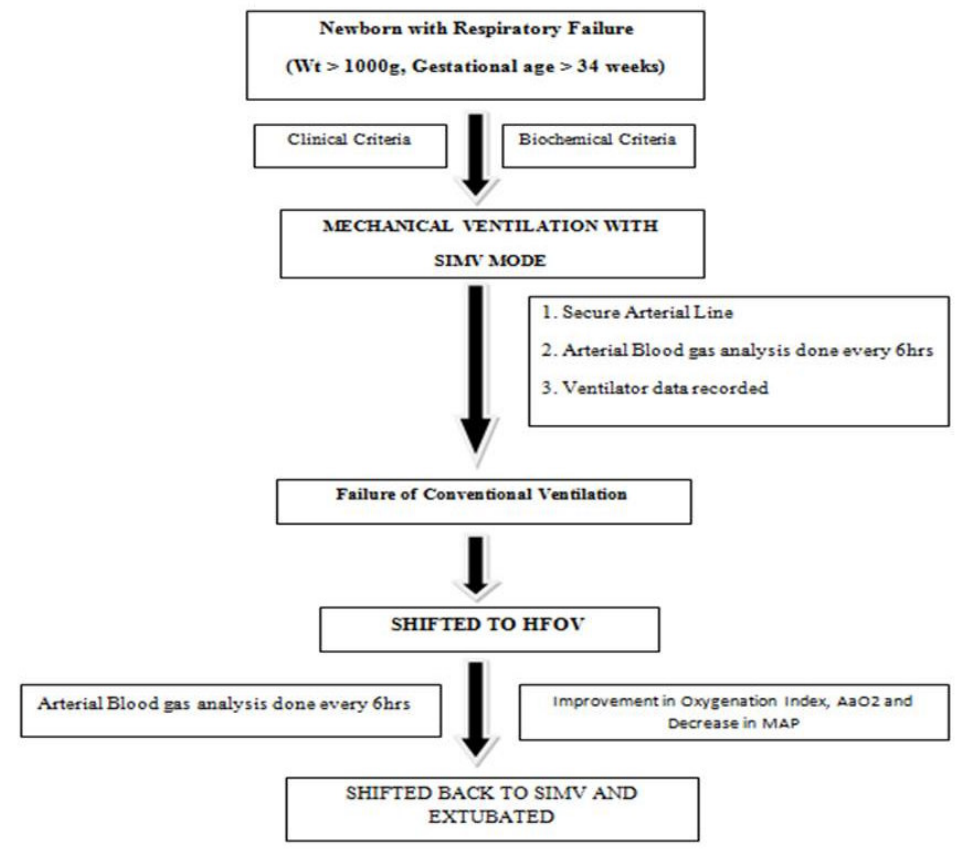

Figure 1: Flowchart of protocol followed in the study. 
[Clinical criteria included chest retractions, grunting, respiratory rate $>60$ breaths/min, central cyanosis, intractable apnea, decreased activity and movement. Laboratory criteria included $\mathrm{PaCo} 2>60 \mathrm{mmHg}, \mathrm{PaO} 2<50 \mathrm{mmHg}$ with a Fio 2 of 1.0, $p$ H less than 7.20, SIMV- Synchronised Intermittent Mandatory Ventilation].

Each baby with impending respiratory failure was ventilated conventionally for minimum of six hours and if the baby deteriorates recruitment of the lung was prioritized by increasing the PEEP to a higher level of 7, followed by arterial blood gas and a chest $X$-ray. If the X-ray showed under-inflation, then PEEP was increased to higher levels. All the other causes like tube displacement, obstruction, equipment failure, air leak was ruled out before shifting over to HFOV (SOPHIE-Stephan ventilator used in this study). On HFOV, babies were initially started on a MAP of $2 \mathrm{~cm}$ higher than the MAP on conventional ventilator and MAP increased until a saturation of $>95 \%$ was achieved (after which priority was given to wean off $\mathrm{FiO} 2$ ).

The amplitude was adjusted based on the chest wriggle; frequency was started at $12 \mathrm{~Hz}$ for the preterm babies and at 10 $\mathrm{Hz}$ for term babies and adjusted later based on $\mathrm{ABG}$ analysis. Neonates were again weaned off to conventional mode of ventilation when target goals of oxygenation and ventilation were reached.

Primary outcome of improvement in oxygenation index (OI), alveolar arterial oxygen gradient were analysed with secondary outcome of survival using the formula enumerated. Outcome parameters measured between CV and HFOV were comparison of MAP delivered, alveolar arterial oxygen gradient, OI, and duration of ventilation.

A-a gradient $=\mathrm{FiO} 2 \times\left(\mathrm{Patm}-\mathrm{PH}_{2} \mathrm{O}\right)-\left(\mathrm{PaCO}_{2} / 0.8\right)-\mathrm{PaO}_{2}$ and $\mathrm{OI}=(\mathrm{MAPxFiO} 2 \times 100) / \mathrm{PO} 2$ wherein $\mathrm{Patm}-$ atmospheric pressure, $\mathrm{PH} 2 \mathrm{O}-$ Water vapour pressure, MAP-Mean airway pressure, FiO2-Fraction of inspired oxygen, and PO2Arterial PO2.

\section{Results}

Among 31 neonates, $20(64.5 \%)$ were males and 11(35.5\%) females. $21(71 \%)$ neonates were admitted at $0-12$ hrs of age, $3(9.7 \%)$ at $12-24 \mathrm{hrs}, 1(3.2 \%)$ at $24-72 \mathrm{hrs}$ and $5(16.1 \%)$ at more than $72 \mathrm{hrs}$ of age as per their presentation to the intensive unit. Mean duration of hospitalisation was 16 days in 15 babies who required HFOV as rescue strategy after failed conventional mode of ventilation. The total duration of ventilation including both HFOV and conventional ventilation was 6 days on average for 15 babies who were successfully extubated after rescue therapy with HFOV. In16 babies who failed HFOV mean duration of ventilation was 2 days.

Among 26 term neonates appropriate for gestational age, in 9 neonates $(29 \%)$ the primary diagnosis was primary pulmonary hypertension (PPHN), next condition seen in 8 neonates $(25 \%)$ was concurrent occurence of sepsis with congenital pneumonia, multiorgan dysfuntion and pulmonary hemorrhage.

Meconium aspiration syndrome was noted in $6(19.3)$, congenital pneumonia in $2(6.4 \%)$, and one neonate was diagnosed birth asphyxia with pulmonary hemorrhage. In $5(16.1 \%)$ Late preterm neonates the underlying condition was congenital pneumonia, multiorgan dysfuntion and pulmonary hemorrhage.

Thus PPHN was the main indication in the present study for which HFOV was initiated.

31 babies ventilated with HFOV, 15 (48.4\%) recovered and were successfully shifted back to SIMV and extubated, while 16 babies (51.6\%) did not recover. 15 ( 57\% ) term babies of 26 enrolled recovered with HFOV whereas all late preterm babies constituting 5 (16.1\%) had poor outcome.

Comparative outcome based on primary diagnosis showed that 7 out of 9 neonates with PPHN (78\%), 6 with MAS $(100 \%), 2$ with congenital pneumonia $(100 \%)$ recovered while those with pulmonary hemorrhage succumbed.

Parameter outcome analysis: Figure 2a shows variation of MAP with OI on CV before shifting to HFOV wherein the plotting showed that even on increasing MAP on CV, OI didn't improve while Figure $2 b$ shows variation of MAP with OI after shift. The OI decreased significantly after shift. 


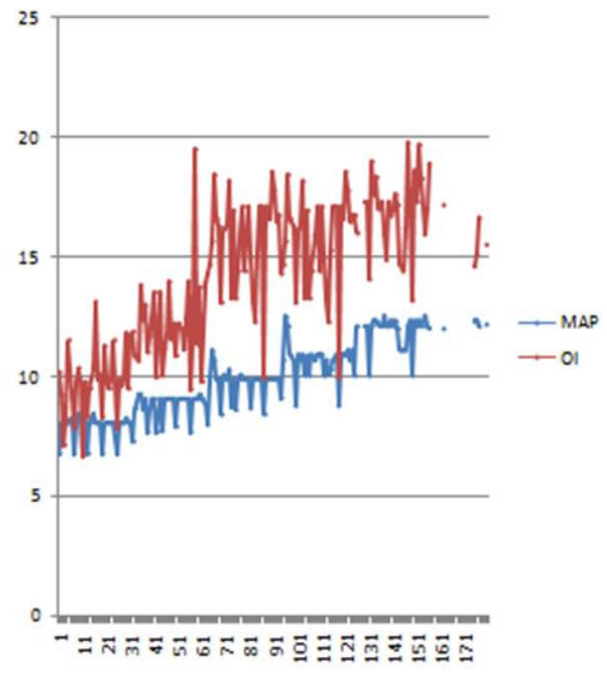

Fig 2(a): MAP with OI on CV before shifting to HFOV

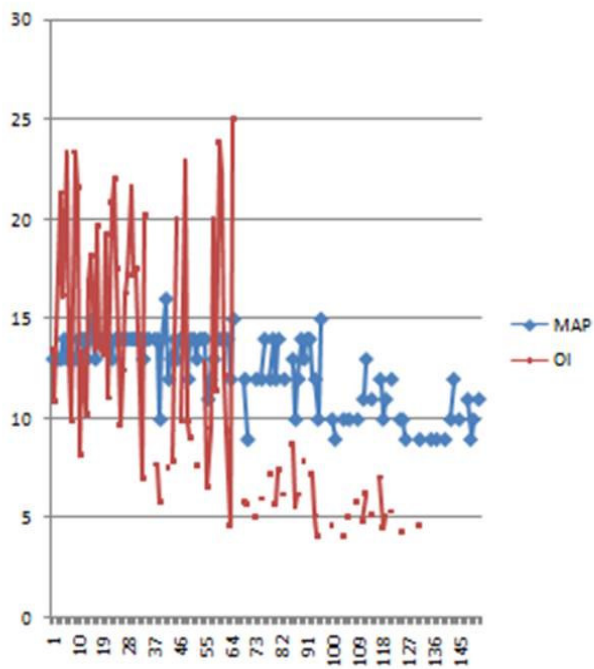

Fig 2(b): MAP with OI on CV after shifting to HFOV

Figure 2: (a) MAP with OI on CV before shifting to HFOV (b) after shifting to HFOV

Figure 3 shows the variation of $\mathrm{A}-\mathrm{aDO}_{2}\left(\mathrm{~A}-\mathrm{aDO}_{2}\right.$ plotted along y axis against time in $\mathrm{x}$ axis $)$ after shift; there is fall in AaDo 2 at 12, 18 and 24 hrs. Among those neonates who responded with HFOV majority showed improvement at $12 \mathrm{hrs}$ and $18 \mathrm{hrs}$ assessment set point enabling shift to SIMV mode.

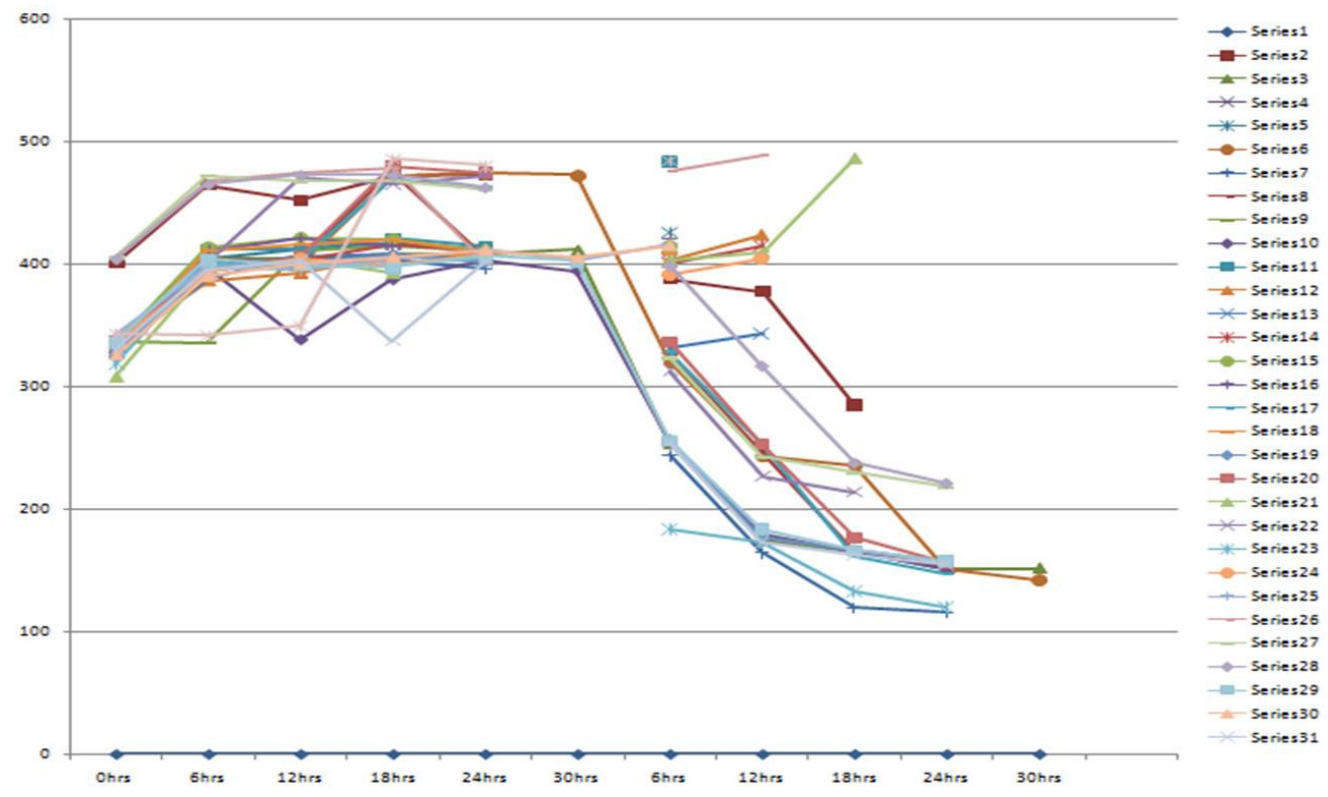

Figure 3: Line diagram showing variation of $\mathrm{A}_{-} \mathrm{aDO}_{2}\left(\mathrm{~A}-\mathrm{aDO} \mathrm{O}_{2}\right.$ plotted along $\mathrm{y}$ axis against time in $\mathrm{x}$ axis)

$\mathrm{P}$ value of paired samples with $\mathrm{OI}$ and $\mathrm{A}-\mathrm{aDO}_{2}$ were also significant $(<0.001)$ at 12,18 and $24 \mathrm{hrs}$. Table 1 shows that paired sample analysis of OI at 12 and $24 \mathrm{hrs}$ had a mean value $12.23+6.0$ and $16.69+1.56$ in 20 neonates with p value 0.004 and at $18 \mathrm{hrs}$ with $24 \mathrm{hrs}$ also $\mathrm{p}$ values were $<0.001$ with mean values of $6.57+1.34$ and $16.70+1.79$ in 15 neonates highlighting the outcome of OI by shift to HFOV as beneficial as a rescue mode. Similarly, A-aDO 2 values had mean of $355.38+80.1$ in 29 neonates at $6 \mathrm{hrs}, 273+101.76$ in 20 neonates at $12 \mathrm{hrs}, 158+30.42$ in 13 neonates at 24hrs paired with 24 hrs respectively. $\mathrm{P}$ value $<0.001$ in each of these was found significant, thus even $\mathrm{A}-\mathrm{aDO}_{2}$ also showed improvement after shift that was statistically better to $\mathrm{CV}$. 
Table-1: Paired samples statistics denotes statistical significant $p$ value with OI and AaDo2 after shifting to HFOV from conventional ventilation at 12, 18 and 24 hrs with significant improvement.

\begin{tabular}{|c|c|c|c|c|c|}
\hline & & Mean & $\mathbf{N}$ & Std. Deviation & p-value \\
\hline \multirow[t]{2}{*}{ Pair 1} & $24 \mathrm{OI}$ & 16.8890 & 29 & 1.57875 & 0.190 \\
\hline & $6 \mathrm{OI}$ & 15.8672 & 29 & 4.41169 & \\
\hline \multirow[t]{2}{*}{ Pair 2} & $24 \mathrm{OI}$ & 16.6965 & 20 & 1.65396 & 0.004 \\
\hline & $12 \mathrm{OI}$ & 12.23965 & 20 & 6.000110 & \\
\hline \multirow[t]{2}{*}{ Pair 3} & $24 \mathrm{OI}$ & 16.7027 & 15 & 1.79550 & $<0.001$ \\
\hline & $18 \mathrm{OI}$ & 6.57633 & 15 & 1.347101 & \\
\hline \multirow[t]{2}{*}{ Pair 4} & $24 \mathrm{OI}$ & 16.5015 & 13 & 1.80715 & $<0.001$ \\
\hline & $24 \mathrm{OI}$ & 5.1669 & 13 & .82905 & \\
\hline \multirow[t]{2}{*}{ Pair 5} & $24 \mathrm{OI}$ & 15.4100 & 2 & 1.89505 & 0.090 \\
\hline & $30 \mathrm{OI}$ & 4.4750 & 2 & .27577 & \\
\hline \multirow[t]{2}{*}{ Pair 6} & $24 \mathrm{AaDO} 2$ & 424.3966 & 29 & 29.15036 & $<0.001$ \\
\hline & 6AaDO2 & 355.3828 & 29 & 80.12845 & \\
\hline \multirow[t]{2}{*}{ Pair 7} & $24 \mathrm{AaDO} 2$ & 426.8625 & 20 & 31.71983 & $<0.001$ \\
\hline & $12 \mathrm{AaDO} 2$ & 273.1625 & 20 & 101.76522 & \\
\hline \multirow[t]{2}{*}{ Pair 8} & $24 \mathrm{AaDO} 2$ & 433.8333 & 15 & 33.96409 & $<0.001$ \\
\hline & 18AaDO2 & 185.6167 & 15 & 44.79834 & \\
\hline \multirow[t]{2}{*}{ Pair 9} & $24 \mathrm{AaDO} 2$ & 427.8077 & 13 & 32.41482 & $<0.001$ \\
\hline & $24 \mathrm{AaDO} 2$ & 158.0000 & 13 & 30.42854 & \\
\hline \multirow[t]{2}{*}{ Pair 10} & $24 \mathrm{AaDO} 2$ & 441.0000 & 2 & 46.66905 & 0.081 \\
\hline & $30 \mathrm{AaDO} 2$ & 146.750 & 2 & 6.7175 & \\
\hline \multirow[t]{2}{*}{ Pair 11} & $24 \mathrm{AaDO} 2$ & . & 0 & . & \\
\hline & $36 \mathrm{AaDO} 2$ & . & 0 & . & \\
\hline
\end{tabular}

(OI:Oxygenation Index, AaDO2: Airway arterial pressure, values at 6,8,12,24,30, 36 paired with 24hrs)

\section{Discussion}

HFOV is a new mode of mechanical ventilation which by safer use of mean airway pressure that is higher than that used during conventional ventilation. The available data on this modality of ventilation is limited hence the clinical application and appropriate target remains inconclusive. A recent Cochrane review suggested that this mode ventilation can be used as rescue therapy after failure of conventional ventilation as a lung protective strategy [4].

In study by Kyung et al, Pulmonary haemorrhage and air leak syndrome were the common indication of HFOV [14]. Johan S Clarissa et al, study showed common cause as respiratory distress syndrome, meconium aspiration syndrome [15]. In the present study, the common diagnosis was found to be PPHN, Pulmonary hemorrhage and meconium aspiration and congenital pneumonia. Majority of neonates with primary diagnosis as meconium aspiration syndrome, congenital pneumonia showed 100\% recovery. PPHN babies had 78\% recovery, while babies with pulmonary haemorrhage secondary to sepsis and birth asphyxia in both term and late preterm group had poor outcome.

Poddutoor KP et al study showed fifty seven babies $(58.77 \%)$ survival and high mortality in $<28$ weeks neonates, especially babies with pulmonary hemorrhage, sepsis and CDH [16]. Pulmonary hemorrhage, sepsis were also common primary diagnosis in this study that affected the outcome and mortality.

The mean airway pressure was compared 6 hourly on both conventional ventilation and high frequency oscillatory ventilation. There was significant decline in requirement of mean airway pressure to improve oxygenation index in 15 babies shifted to HFOV. The $\mathrm{A}-\mathrm{aDO}_{2}$ gradient significantly improved over time in 15 babies after shifting to high frequency oscillatory ventilation statistically significant $\mathrm{p}$ value $(<0.001)$ was obtained at $6 \mathrm{hrs} 12 \mathrm{hrs}$ and $24 \mathrm{hrs}$ post HFOV. Similar improvement of arterial alveolar oxygen gradient was seen by Poddutoor KP et al and Kyung lee et al at 6 hrs respectively in their studies. $[14,15,16]$. 
Jaballah et al, found improvement in OI after $1 \mathrm{hr}$ of HFOV in neonates treated with respiratory failure while our study results were similar to response in Sainaik et al, and Kyung lee et al, where 6 hours after institution of HFOV, OI improvement was seen $[14,17,18]$. The response was statistically significant proving the efficacy of HFOV as rescue therapy. Thus, improvement in oxygenation index and $\mathrm{A}-\mathrm{aDO}_{2}, 15$ babies after shifting to HFOV with decrease in requirement of mean airway pressure to improve oxygenation index and aAD02 on HFOV makes it a mode to consider for favourable outcome on failing $\mathrm{CV}$.

In the present study 15 babies recovered with HFOV as rescue therapy after failed CV (Table 2). In comparison with other studies, the outcome in our study was $50 \%$. This could be due to small sample size as compared to other studies and the primary diagnosis in the babies that affected outcome.

Table-2: Comparison of outcome with other studies.

\begin{tabular}{|c|c|c|c|c|}
\hline Studies & $\begin{array}{c}\text { Sample } \\
\text { size }\end{array}$ & $\begin{array}{c}\text { Babies ventilated with } \\
\text { HFOV as rescue therapy }\end{array}$ & $\begin{array}{c}\text { Mean duration of } \\
\text { HFOV }\end{array}$ & Survival \\
\hline $\begin{array}{c}\text { Poddutoor KP et } \\
\text { al [16] }\end{array}$ & 675 & 97 & $62 \mathrm{hrs}$ & 57 \\
\hline $\begin{array}{c}\text { Aggarwal et al } \\
{[19]}\end{array}$ & 9 & 9 & $120 \mathrm{hrs}$ & 4 \\
\hline Diwakar et al [20] & 18 & 13 & $71 \mathrm{hrs}$ & 26 \\
\hline Clarissa et al [15] & 34 & 34 & $90 \mathrm{hrs}$ & $\mathbf{4 8 ~ h r s}$ \\
\hline Present study & $\mathbf{3 1}$ & $\mathbf{3 1}$ & $\mathbf{1 5}$ \\
\hline
\end{tabular}

There was no complications i.e. air leak syndromes, chronic lung disease, interventricular haemorrhage, noticed on 15 babies who were successfully treated with HFOV.

\section{Conclusion}

HFOV is an alternative form of mechanical ventilation that can be delivered on critical care units. Limitations of $\mathrm{CV}$ in treatment of newborns with respiratory failure demand the development of lung protective strategies in the form of HFOV. The present study shows that high frequency oscillatory ventilation can be used as rescue therapy for neonates after failing conventional ventilation. In intensive neonatal set up where facilities like inhaled nitric oxide or ECMO are not available HFOV is a promising modality.

Limitations: Small size of the sample

\section{Recommendations}

1. In the present study MAP of 12 in term babies was taken as cut off for shifting to HFOV, consideration should be given to initiate HFOV at lower MAP which might affect outcome as rescue therapy.

2. Oxygenation index of 14 and $\mathrm{AaDO} 2$ of 350 was taken as cut off for starting HFOV, promising trials still required to initiate $\mathrm{HFOV}$ at lower oxygenation index and $\mathrm{A}-\mathrm{aDO}_{2}$.

3. Incidence of oxygen requirement at 28 days (Bronchopulmonary dysplasia) was substantially lower in babies ventilated with HFOV as rescue therapy.
4. Incidence of intraventricular haemorrhage was substantially lower in babies ventilated with HFOV as rescue therapy.

5. It was noted that improvement in oxygenation (reducing OI) observed after shifting to HFOV does not necessarily improve the survival.

Conflict of interest: None

Source of funding: Nil

\section{References}

1. Lawn J, Cousens S, Zupan J. 4 million neonatal deaths: When? Where? Why? Lancet. 2005; 365 (9462): 891 - 900. DOI: 10. 1016 /s0140 - 6736 (05) 71048-5.

2. WHO. Perinatal and Neonatal Mortality for the Year 2000: Country, Regional and Global Estimates.WHO; Geneva: 2006.http://whqlibdoc.who. int/publications /2006/9241563206_eng.pdf.

3. Neogi SB, Malhotra S, Zodpey S, Mohan P. Assessment of special care newborn units in India. J Health Popul Nutr. 2011; 29(5): 500-9. DOI: 10.3329/ jhpn.v29i5.8904. 
4. Bhuta T, Clark RH, Henderson-Smart DJ. Rescue high frequency oscillatory ventilation $\mathrm{v} / \mathrm{s}$ conventional ventilation for infants with severe pulmonary dysfunction born at or near term. Cochrane Database Syst Rev. 2001;(1): CD002974 PMID:11279790. DOI: 10.1002/14651858.CD002974

5. Yildizdas D, Yapicioglu H, Bayram I, Yilmaz L, Sertdemir Y. High frequency oscillatory ventilation for acute respiratory distress syndrome. Indian J Pediatr. 2009;76:921-7. DOI--10.1007/s12098--009-0151-9.

6. Kessel I, Waisman D, Barnet-Grinnes O, Ben Ari TZ, Rotschild A. Benefits of high frequency oscillatory ventilation for premature infants. Isr Med Assoc J. 2010;12(3):144-9.

7. Truog WE, Standaert TA, Murphy JH, Woodrum DE, Hodson WA. Effect of prolonged high frequency oscillatory ventilation in premature primates with experimental hyaline membrane disease. Am Rev Respir Dis 1984;130:76-80.

8. de Lemos RA, Coalson JJ, Gerstmann DR, Null Jr. DM, Ackerman NB, Escobedo MB et al. Ventilatory management of infant baboons with hyaline membrane disease; the use of high frequency ventilation. Pediatr Res1987;21(6):594-602. DOI: 10.1203/00006450198706000-00018

9. Weavind L, Wenker OC. Newer modes of Ventilation: An Overview. The Internet Journal of Anesthesiology 1999; Volume 4 Number 4. http:/ /ispub. com/IJA/4/4/10738.

10. Hamel DS, Cheifetz IM. High-frequency oscillatory ventilation-a clinical approach.SAAJC2005;Vol 21(1):15-25.

11. Schindler M, Seear M. The effects of lung mechanics on gas transport during high frequency oscillation. Pediatr Pulmonol. 1991;11(4): 335-9. DOI: 10.1002/ppul.1950110410

12. Slutsky AS, Kamm RD, Rossing TH, Loring SH, Lehr J, Shapiro AH et al. Effects of frequency, tidal volume and lung volume on $\mathrm{CO} 2$ elimination in dogs by high frequency $(2-30 \mathrm{~Hz})$, low tidal volume ventilation. J Clin Invest. 1981; 68(6):1475-84. DOI: 10.1007/s12098-009-0151-9

13. Bryan AC, Froese AB. Reflections on the HiFi trial(editorial). Pediatrics. 1991;87:565-7.

14. Lee EK, Chang YS, Park WS. High frequency oscillatory ventilation as a rescue therapy of severe neonatal respiratory failure. Korean $\mathrm{J}$ Pediatr. 1998;41(4):456-65

15. Smith J, Pieper CH, Kirsten GF, Maree D, Van Zyl J, Pretorius ML. High frequency oscillatory ventilation - rescue treatment for infants with severe respiratory failure. S. Afr. Med. J 1998;88(4):484-9.

16. Poddutoor PK, Chirla DK, Sachane K, Shaik FA, Venkatalakshmi A. Rescue high frequency oscillation in neonates with acute respiratory failure. Indian Pediatr. 2011;48(6):467-70. DOI: 10.1007/s13312-0110073-2

17. Ben Jaballah N, Mnif K, Khaldi A, Bouziri A, Belhadj S, Hamdi A. High frequency oscillatory ventilation in term and near term infants with acute respiratory failure: early rescue use. Am J Perinatol. 2006;23:403-11. DOI: 10.1055/s-2006-951289

18. Sarnaik AP, Meert KL, Pappas MD, Simpson PM, Lieh-lah MW, Mary W, et al. Predicting outcome in children with severe acute respiratory failure treated with high-frequency ventilation. Crit Care Med. 1996;24:1396-402.DOI:10.1097/00003246-19950100100353.

19. Aggarwal R, Downe L. Use of High frequency ventilation as a rescue measure in premature babies with severe respiratory failure. Indian Pediatr. 2000;37:522-6.

20. Diwakar KK, Bhaskaranand N. Early experiences with high frequency oscillatory ventilation in neonates. Indian Pediatr. 1999;36:379-83.

\section{How to cite this article?}

Venkatesh Murthy D V, Benakappa N, Benakappa A. Role of High frequency oscillatory mode of ventilation (HFOV) as a rescue treatment in newborns with impending respiratory failure after failed conventional mode of ventilation. Int. $\mathrm{J}$ PediatrRes.2016;3(11):842-848.doi:10.17511/ijpr.2016.i11.13. 